\title{
Microbial communities of bulk and Eschscholzia californica rhizosphere soils at two altitudes in Central Chile
}

\author{
M. de Armas-Ricard ${ }^{1 *}$, J. Orlando ${ }^{1}$, R. Bustamante ${ }^{1,2}$, M. Carú ${ }^{1}$ \\ ${ }^{I}$ Department of Ecological Sciences, Faculty of Sciences, Universidad de Chile, Santiago, Chile. \\ ${ }^{2}$ Institute of Ecology and Biodiversity, Faculty of Sciences, Universidad de Chile, Santiago, Chile. \\ *Corresponding autor: merlydearmas@gmail.com
}

\begin{abstract}
Despite several reports point out a rhizosphere effect shaping soil microbial communities and others an effect of altitude on plant phenotypic features, currently little is known about the impact of elevational patterns on the diversity of soil microbial communities. In this study, diversity of soil microbial communities was assessed in samples derived of bulk and rhizosphere soils associated to Californian poppy (Eschscholzia californica Cham.) populations at 1000 and 2000 m.a.s.l in Central Chile. E. californica, a native plant of North America, is considered a successful invader in Mediterranean ecosystems worldwide but its effect on diversity of soil microbial communities is yet unknown. Microbial diversity was evaluated at genetic level through T-RFLP (terminal restriction fragment length polymorphisms) using bacterial, archaeal and fungal molecular markers, and at metabolic level using CLPP (community-level physiological profiles). At genetic level, microbial diversities of bulk and rhizosphere soils at lower altitude were similar, although at higher altitude microbial diversity of both types of soils was different, suggesting a plant filtering effect more notorious at higher altitude. At metabolic level, microbial diversity of rhizosphere soils were similar independently of the altitude, suggesting a plant filtering effect that exceeds the altitude effect observed in the case of the bulk soil.
\end{abstract}

Keywords: Eschscholzia californica, soil microbial community, metabolic diversity, genetic diversity, altitude, rhizosphere effect

\section{Introduction}

Genetic and metabolic diversity of soil microbial communities depends on multiples resources and numerous environmental factors such as organic material, moisture content, $\mathrm{pH}$, among others, including altitude, a factor whose effects on microorganisms are not yet well-known. The effect of elevational gradients on plant and animal diversity has been extensively documented (e.g. Lomolino, 2001; 
Grytnes, 2003; McCain, 2005); however information on the effects of altitude on patterns of microbial diversity is newly emerging. Some reports pointed out that soil bacterial diversity patterns exhibit nonsignificant differences along an elevational gradient, in contrast to significant changes in diversity of macroorganisms (Fierer, et al., 2011; Shen et al., 2013). Conversely, other studies suggest that diversity of soil bacterial (Shen et al., 2015; Singh et al., 2014) and archaeal (Wang et al., 2015) communities were affected by elevations or that at least the bacterial group acidobacteria was affected (Zhang et al., 2014). On the other hand, the effect of altitude on soil microbial communities may be modulated by vegetation growing on these sites since rhizosphere provides a habitat different to bulk soil without plant cover for microbial communities (Kuske et al., 2002; Orlando et al., 2007). Several reports suggest that vegetation has an important role shaping the soil bacterial communities (Shen et al., 2013), meanwhile the microbiota produces secondary metabolites that improve plant nutrition and protect against phytopathogens (Martínez-Viveros et al., 2010).

Nowadays, some authors pointed out that invasive plants markedly alter the chemical and physical properties of soil (Weidenhamer and Callaway, 2010), which in turn would disturb the diversity of soil microbial communities (Batten et al., 2006; Min et al., 2013). Particularly, in Chile 700 species of invasive plants have been described (Quiroz et al., 2009) within them E. californica, the Californian poppy, is an herbaceous plant native of the West Coast of North America and it is considered a successful invader in Mediterranean ecosystems worldwide (Leger and Rice, 2007). It was introduced in the Central Region of Chile in the late nineteenth century and 100 years later is widely distributed in the country from $30^{\circ} \mathrm{S}$ to $38^{\circ} \mathrm{S}$ and from sea level to 2200 m.a.s.l.
(Arroyo et al., 2000). Even though E. californica is a very common plant in California and Chile, studies conducted to address its ecology are relatively scarce and particularly reported significant differences in reproductive and vegetative characteristics among $E$. californica populations located at different altitudes in Central Chile (Peña-Gómez and Bustamante, 2012; Castillo et al., 2013)

The effect of invasive plants on soil microbiota is a topic of current interest, as examples, in California the invasive yellow star-thistle, Centaurea solstitialis L., increases diversity of sulfur-oxidizing bacteria and sulfate-reducing bacteria (Batten et al., 2006); the invasive cheat grass Bromus tectorum L., changes the composition of the soil bacterial community by decreasing denitrifying bacteria abundance in Utah (Kuske et al., 2002); and the invasive blue wattle Acacia dealbata Link, increases bacterial richness and decreases fungal richness depending on the studied ecosystem in Northwest Spain (Lorenzo et al., 2010). Moreover, it is proposed that invasive plants may have particularly strong effects on rhizosphere microbiota through their secondary metabolites (Vivanco et al., 2004; Badri and Vivanco, 2009). In fact, $E$. californica produces various types of isoquinoline alkaloids (Fabre et al., 2000), such as sanguinarine, a potent antimicrobial agent (Alcantara et al., 2005). Since the rhizosphere is a well-defined microhabitat, different to the neighboring bulk soil, revealing the effect of the vegetation on the microbial community structure (Kuske et al., 2002; Orlando et al., 2007; Garbeva et al., 2008), then we hypothesized that E. californica could act as an environmental filter influencing the rhizosphere microbial community and masking the altitudinal effect. Therefore this study was focused on evaluate genetic and metabolic diversity patterns of soil microbial communities growing in bulk soil without plant cover and in E. californica rhizosphere 
soil. The aim of this work was to determine patterns of genetic and metabolic diversities of soil microbial communities at two altitudes, in samples derived of bulk and rhizosphere soils associated to E. californica populations located at 1000 and 2000 m.a.s.1 in the Andes mountain range, Central Chile. The microbial genetic diversity was evaluated through T-RFLP (terminal restriction fragment length polymorphisms) (Liu et al., 1997) using bacterial, archaeal and fungal molecular markers, whilst the metabolic diversity was assessed by CLPP (community-level physiological profiles) (Garland and Mills, 1991).

\section{Materials and Methods}

\subsection{Study sites and soil sampling}

Soil samples were collected in the locality of Farellones $\left(33^{\circ} 21^{\prime} \mathrm{S} ; 70^{\circ} 19^{\prime} \mathrm{W}\right)$ at two different altitudes: site 1 at 1000 m.a.s.l. and site 2 at 2000 m.a.s.1.; these sampling sites are located in the Andean range of Central Chile which is characterized by a dry Mediterranean climate with winter rains. At both altitudes linear transects within the area where the invasive plant was plentiful (E. californica rhizosphere soils, RS) and where there were not invasive or native plants (bulk soils, BS) were randomly disposed. The study was conducted with composite soil samples, in triplicate, in order to reduce the small-scale spatial heterogeneity; each composite sample was obtained mixing 10 independent samples, which were taken in the respective transect and separated from each other by $1 \mathrm{~m}$. The sampling was performed during spring 2010, coinciding with the plant flowering. BS samples were obtained from the top soil to a depth of about $10 \mathrm{~cm}$; whereas RS samples were collected from soil adhering to the roots (ca. $10 \mathrm{~cm}$ length) of E. californica flowering plants with a height of 20-30 $\mathrm{cm}$. All samples were stored at $4^{\circ} \mathrm{C}$ until analyses.

\subsection{Edaphic factors}

For each, composite soil sample edaphic factors $\mathrm{pH}$, moisture content (MC), organic matter $(\mathrm{OM})$ and nitrate content $\left(\left[\mathrm{NO}_{3}^{-}\right]\right)$were determined. Briefly, $\mathrm{pH}$ was measured using potentiometry; $\mathrm{MC}$ and OM were calculated gravimetrically before and after desiccation and calcination, respectively; and $\left[\mathrm{NO}_{3}^{-}\right]$ was determined by colorimetry.

\subsection{DNA extraction and PCR conditions}

DNA was extracted from $0.25 \mathrm{~g}$ of each composite soil sample using the Power Soil ${ }^{\mathrm{TM}}$ DNA Isolation kit (MoBio Laboratories Inc., CA, USA) according to the manufacturer's instructions. The quality and integrity of the extracted DNA were visualized in $0.8 \%(\mathrm{w} / \mathrm{v})$ agarose gels in TAE $1 \mathrm{X}$ buffer (40 mM Tris-acetate, 1 mM EDTA [pH 8.0]) stained with GelRed ${ }^{\mathrm{TM}}$ (Biotium, CA, USA). All DNA samples were stored at $-20^{\circ} \mathrm{C}$ until analysis. Therefore, the bacterial 16S rRNA genes (B-16S rDNA) were amplified with primers fD1-FAM (carboxyfluorescein) and rP2 (Weisburg et al., 1991). The archaea 116S rRNA(A-16S rDNA) and the fungal $18 \mathrm{~S}$ rRNA (F-18S rDNA) genes were amplified using nested PCR approaches. The A-16S rDNA amplifications were carried out using in the first reaction primers 23FPL (Bintrim et al., 1997) and UA1204R (Baker et al., 2003) and in the second reaction primers A571F and UA1204R-FAM (Baker et al., 2003). The F-18S rDNA amplifications were performed using in the first reaction primers NS1 and EF3 (Hagn et al., 2003) and in the second reaction primers EF4 and EF3-FAM (Smit et al., 1999). All the amplifications were performed according to the cited literature recommendations and using the $\mathrm{GoTaq}^{\circledR}$ Green Master Mix (GoTaq ${ }^{\circledR}$ DNA polymerase in $1 \mathrm{X}$

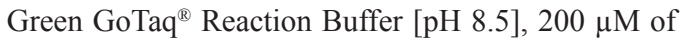
each dNTP and $1.5 \mathrm{mM} \mathrm{MgCl}_{2}$ ) (Promega, WI, USA) 
in a Maxygene thermo cycler (Axygen, CA, USA). The concentration and quality of the amplicons were determined electrophoretically as described above except that $1.2 \%(\mathrm{w} / \mathrm{v})$ agarose gels were used.

\subsection{Terminal restriction fragment length polymorphisms (T-RFLP)}

Terminal restriction fragment length polymorphisms (T-RFLP) were used to evaluate genetic diversity of microbial communities in each soil sample. The amplicons from each molecular marker were hydrolyzed overnight with the restriction enzymes HaeIII and MspI in the cases of B-16S rDNA and F-18S rDNA, and HaeIII and BstUI in the case of A-16S rDNA (Fermentas, NY, USA). Terminal restriction fragments (T-RFs) were separated on an automated Genetic Analyzer ABI3730XL (Applied Biosystems; Macrogen Inc., Seoul, Korea). The length of the fluorescently labeled T-RFs was determined by comparison with the GeneScan ${ }^{\mathrm{TM}}$ 1200 LIZ $^{\circledR}$ size-standard using the GeneScan 3.71 software (Applied Biosystems, Darmstadt, Germany). Peaks with a fluorescence over $100 \mathrm{U}$ and larger than $60 \mathrm{bp}$ were analyzed by peak height. Patterns from different samples were normalized to identical total fluorescence units by an iterative standardization procedure. Relative abundance of T-RFs, as percentage, was determined by calculating the ratio between the height of a given peak and the normalized total peak height of each sample. Shannon $\left(\mathrm{H}^{\prime}\right)$ indices were calculated for each sample using the PAST software (available at: http://nhm2.uio.no/ norlex/past/download.html). In addition, in order to relate the data of the three molecular markers and the edaphic factors, a canonical correspondence (CCA) analysis was conducted using the PAST software.

\subsection{Community-level physiological profiles (CLPP)}

The community-level physiological profiles (CLPP) were used to evaluate the metabolic diversity of the microbial communities in each soil sample using the BIOLOG Eco-Plate ${ }^{\mathrm{TM}}$ system containing 31 different carbon sources and tetrazolium dye as redox indicator. Microbial suspensions were prepared from $1 \mathrm{~g}$ of fresh soil from each sample in $10 \mathrm{ml}$ of sterile PBS buffer (137 mMNaCl, $2.7 \mathrm{mMKCl}, 8 \mathrm{mM}$ $\mathrm{Na}_{2} \mathrm{HPO}_{4}, 2 \mathrm{mM} \mathrm{KH_{2 }} \mathrm{PO}_{4}$ ) and shaking at $150 \mathrm{rpm}$ during $1 \mathrm{~h}$. The plates were inoculated with $100 \mu \mathrm{l}$ of the soil suspensions per well, using one third of the plate for each composite sample replicate, and incubated at $25^{\circ} \mathrm{C}$ during a week. Color development in the individual wells was registered every $24 \mathrm{~h}$ at a wavelength of $590 \mathrm{~nm}$ in an automated plate reader (Epoch, Biotek, Luzern, Switzerland). Absorbance data at the different reading times were corrected by subtracting the first reading (immediately after plate inoculation) to the corresponding response well. The absorbance value of the control well (without carbon source) was subtracted from the absorbance values of each well containing a carbon source and then only the values above 0.1 were considered. The average well color development (AWCD) for each substrate category in the plates was calculated as the mean of the absorbance values of each corresponding well. In order to know the plate incubation time corresponding to the exponential phase, the curves of AWCD versus time were fitted to a modified Gompertz equation using ORIGIN 8.0. Shannon $\left(\mathrm{H}^{\prime}\right)$ indices were calculated for each sample using the PAST software. In order to perform CCA using the PAST software, data were normalized dividing each absorbance value by the AWCD. 


\subsection{Statistical data analyses}

Statistical significant differences of edaphic variables and Shannon $\left(\mathrm{H}^{\prime}\right)$ indices were assessed using oneway ANOVA and the post-hoc Tukey HSD test (GraphPad Software, Inc). The CANOCO software v.4 was used to test the significance of the canonical axes and the influence of each edaphic factor on the variance of the diversity data in the CCA.

\section{Results}

\subsection{Edaphic factors}

At 1000 m.a.s.l. (site 1) statistically non-significant differences were found between both types of soils, bulk (BS) and E. californica rhizosphere (RS) for any of the edaphic variables measured; however, at 2000 m.a.s.l. (site 2), RS had a statistically significant higher moisture content (MC) and $\mathrm{pH}$ than $\mathrm{BS}$ (Table 1). Comparing the soil variables of BS at both altitudes, $\mathrm{MC}$ and $\mathrm{pH}$ at site 2 were lower than at site 1 , although statistically non-significant. Moreover, when comparing $\mathrm{RS}$ at both altitudes, $\mathrm{pH}$ at site 2 was statistically significantly higher than atsite 1 , but statistically non-significant differences in MC were observed despite it was also higher in site 2 than in site 1 (Table 1).

\subsection{Genetic diversity of the soil microbial communities}

In order to determine the genetic diversity of microbial communities of bulk soils (BS) and $E$. californica rhizosphere soils (RS), T-RFLP analyses of the archaeal and bacterial 16S rRNA genes and fungal 18S rRNA genes of each soil sample at both latitudes (sites 1 and 2) were performed.The highest number of T-RFs was obtained with HaeIII for the bacterial (8 T-RFs) and fungal (6 T-RFs) groups, while for the archaeal group the highest number of T-RFs was observed with BstUI (5 T-RFs).The same T-RFs were found in both soil types, for the three molecular markers and the two enzymes used. Assuming that different T-RFs represent distinct operational taxonomic units (OTUs) and considering that differences in the richness of OTUs were not observed, by altitude or soil type, these soils would have a similar microbial composition, at least at the level of the most abundant T-RFs. However, some statistically significantly differences in Shannon diversity indices $\left(\mathrm{H}^{\prime}\right)$ of bacterial and fungal groups were observed due to inequality in the relative abundance of some OTUs (Figure 1a), while archaeal diversity indices showed statistically non-significant differences at both altitudes or in both soil types. Thus, diversity indices of the fungal group from RS at site 2 were statistically significantly higher than the others. Moreover, the lowest values of bacterial genetic diversity indices were observed in RS at both altitudes (sites 1 and 2) (Figure 1a).

The relationship between edaphic parameters and genetic structure of microbial communities in BS and RS at both altitudes was explored using CCA. A sample separation in function of soil type (BS and RS) at site 2 along the axis 1 (CCA1; 88.3\%) was observed; being $\mathrm{MC}$ and $\mathrm{pH}$ the most relevant factors explaining this scattering, the influence of the latter being in addition statistically significant (Figure 2a, Table 2). On the other hand, soil samples from both altitudes were separated along the axis 2 (CCA2; $8.2 \%$ ), being the most influential factor OM (Figure 2a, Table 2). The canonical first axis and the sum of all the canonical axes presented statistical significance (Table 2). Interestingly, at genetic level soil samples at site 1 were grouped together independently of the soil type, although BS and RS samples formed two well-defined groups at site 2, suggesting that the plant filtering effect is more notorious at higher altitude. 
Table 1. Edaphic variables. Values are means \pm standard deviation $(n=3)$. In a row, means values followed by the same letter are not significantly different according to the Tukey HSD test $(P \leq 0.05)$.

\begin{tabular}{|c|c|c|c|c|c|c|c|c|c|c|c|c|}
\hline \multirow{2}{*}{$\begin{array}{l}\text { Edaphic } \\
\text { factor }^{(a)}\end{array}$} & \multicolumn{6}{|c|}{$\mathrm{BS}^{(\mathrm{b})}$} & \multicolumn{6}{|c|}{$\mathrm{RS}$} \\
\hline & \multicolumn{3}{|c|}{ Site 1} & \multicolumn{3}{|c|}{ Site 2} & \multicolumn{3}{|c|}{ Site 1} & \multicolumn{3}{|c|}{ Site 2} \\
\hline $\mathrm{MC}$ & 4.05 & \pm 1.01 & $\mathrm{ab}$ & 2.01 & \pm 0.41 & & 4.26 & \pm 0.37 & $a b$ & 5.74 & \pm 1.71 & b \\
\hline $\mathrm{OM}$ & 9.20 & \pm 4.64 & $\mathrm{a}$ & 5.10 & \pm 1.55 & $\mathrm{a}$ & 7.25 & \pm 2.33 & $\mathrm{a}$ & 4.93 & \pm 0.88 & $\mathrm{a}$ \\
\hline$\left[\mathrm{NO}_{3}^{-}\right]$ & 25.21 & \pm 4.60 & $\mathrm{a}$ & 31.66 & \pm 8.72 & $\mathrm{a}$ & 28.15 & \pm 6.81 & $\mathrm{a}$ & 30.02 & \pm 5.46 & $\mathrm{a}$ \\
\hline $\mathrm{pH}$ & 7.51 & \pm 0.06 & $a b$ & 7.39 & \pm 0.05 & $\mathrm{a}$ & 7.39 & \pm 0.11 & $\mathrm{a}$ & 7.60 & \pm 0.02 & $b$ \\
\hline
\end{tabular}

(a) $\mathrm{MC}$ : moisture content (\%), OM: organic matter (\%) and $\left[\mathrm{NO}_{3}^{-}\right]$: nitrate content $\left(\mu \mathrm{g} / \mathrm{g}_{\mathrm{dw}}\right)$.

(b) BS: bulk soils; RS: E. californica rhizosphere soils.

Table 2. Relationship between the environmental factors and the genetic and functional structures as determined by the canonical correspondence analyses (CCA). CCA scores of both canonical axes (CCA1 and CCA2) and the total variance (\%) were determined using the PAST software. The tests of significance for the canonical axes and the influence of each edaphic factor were calculated using CANOCO.

\begin{tabular}{|c|c|c|c|c|c|c|}
\hline \multirow{3}{*}{ Edaphic factor ${ }^{(a)}$} & \multicolumn{3}{|c|}{ Genetic structure } & \multicolumn{3}{|c|}{ Metabolic structure } \\
\hline & \multicolumn{2}{|c|}{ CCA scores } & \multicolumn{4}{|c|}{ CCA scores } \\
\hline & CCA 1 & CCA 2 & & CCA 1 & CCA2 & \\
\hline $\mathrm{MC}$ & -0.7231 & 0.2724 & 0.051 & 0.6950 & 0.3341 & 0.001 \\
\hline $\mathrm{OM}$ & 0.2790 & 0.4949 & 0.427 & -0.2504 & 0.7197 & 0.285 \\
\hline$\left[\mathrm{NO}_{3}^{-}\right]$ & -0.1172 & -0.1779 & 0.521 & 0.2900 & -0.1438 & 0.711 \\
\hline $\mathrm{pH}$ & -0.5600 & -0.2163 & 0.001 & 0.3118 & 0.0411 & 0.001 \\
\hline Total Variance (\%) & 88.3 & 8.2 & - & 70.0 & 21.5 & - \\
\hline
\end{tabular}

First canonical axis $\quad 0.010 \quad$ First canonical axis $\quad 0.010$

Test of significance

All canonical axes $\quad 0.010 \quad$ All canonical axes $\quad 0.010$

(a) MC: moisture content (\%), OM: organic matter $(\%)$ and $\left[\mathrm{NO}_{3}^{-}\right]$: nitrate content $\left(\mu \mathrm{g} / \mathrm{g}_{\mathrm{dw}}\right)$. 

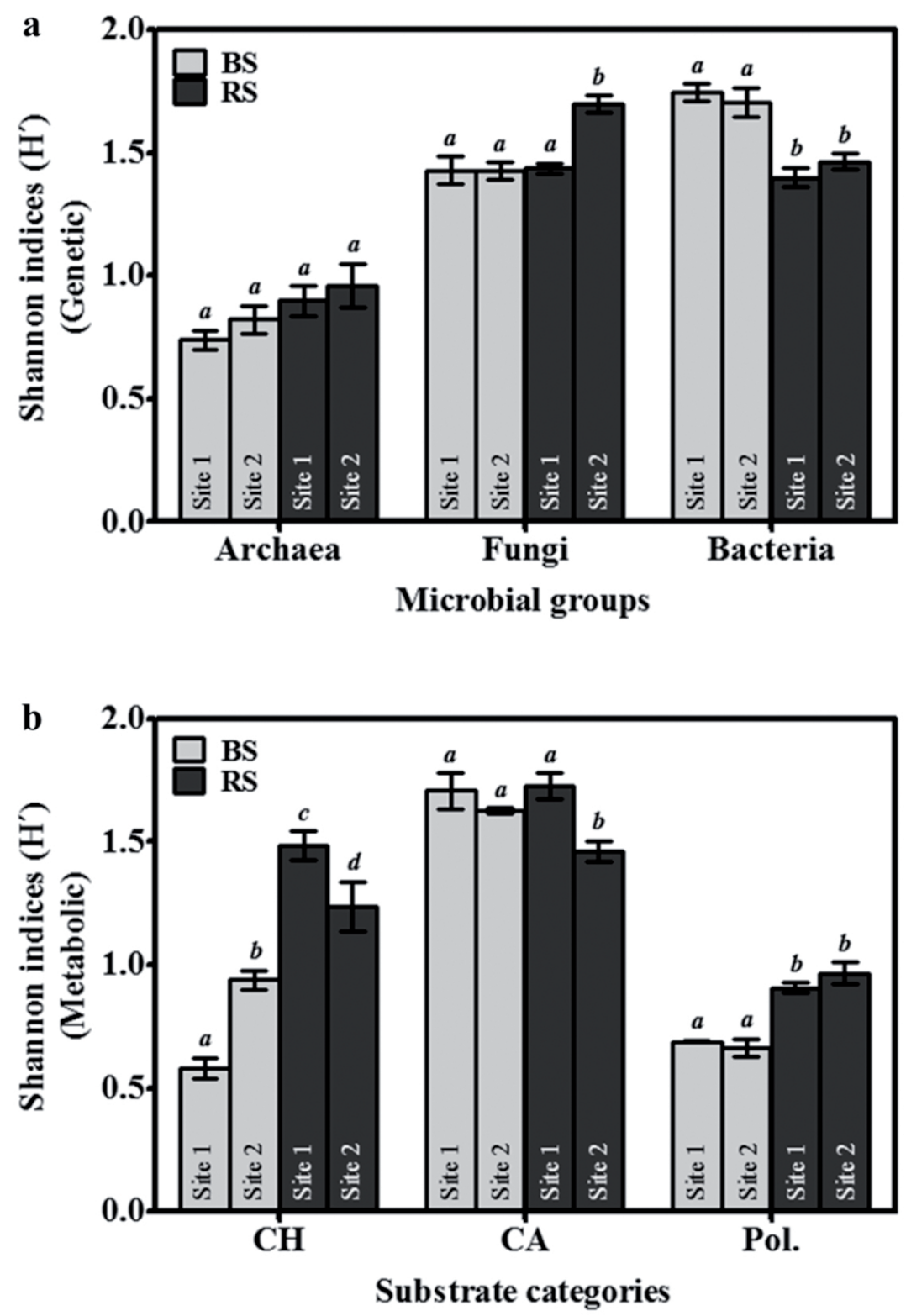

Figure 1. Shannon diversity $\left(\mathrm{H}^{\prime}\right)$ of microbil communities in bulk soils (BS) and Eschscholzia californica rhizosphere soils (RS) at 1000 m.a.s.l. (site 1) and 2000 m.a.s.l. (site2). (a) Genetic diversity indices calculated from T-RFLP. (b) Metabolic diversity and equitability indices calculated from CLPP for specific carbon sources: carbohydrates $(\mathrm{CH})$, carboxylic acids (CA) and polymers (Pol.). Means and standard deviation sof triplicate measures are shown. Within each data set, different letters represent significantly different values according to the Tukey HSD test $(P \leq 0.05)$. 

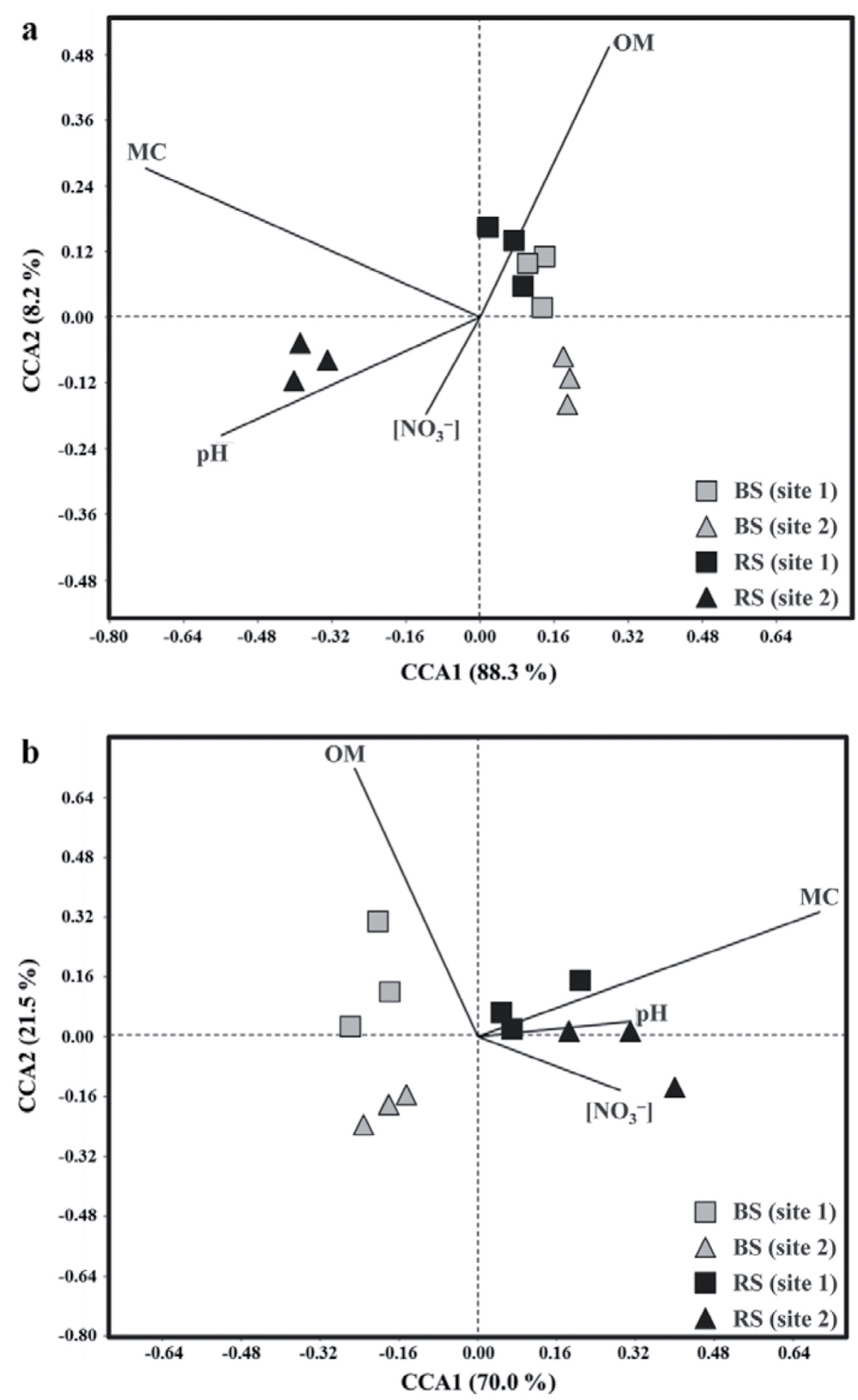

Figure 2. Correspondence canonical analyses (CCA) relating diversity of microbial communities and edaphic factors (MC, moisture content; $\mathrm{OM}$, organic matter; $\left[\mathrm{NO}_{3}^{-}\right]$, nitrate content and $\mathrm{pH}$ ). (a) CCA based on the genetic structure of the microbial communities, (b) CCA based on the metabolic diversity of the microbial communities. 


\subsection{Metabolic diversity of the soil microbial communities}

In order to determine the metabolic diversity of microbial communities of bulk soil (BS) and $E$. californica rhizosphere soil (RS), CLPP analyses were determined according to the number of carbon sources used by each microbial community.

The different carbon sources were grouped into chemical groups and Shannon diversity indices $\left(\mathrm{H}^{\prime}\right)$ for each set of substrates were calculated using the $\mathrm{AWCD}$ at the plate incubation times corresponding to the exponential growth phase. The most outstanding differences regarding metabolic diversity were found in carbohydrates $(\mathrm{CH})$, carboxylic acids $(\mathrm{CA})$ and polymers (Pol.) (Figure 1b). These differences in the use of $\mathrm{CH}$ presented an inverse behavior at both altitudes depending on whether they are BS or RS, increasing their utilization the former and decreasing the latter at higher altitude. On the other hand, respecting CA, RS presented a lower utilization of them but just at site 2. Finally, there were not differences in the use of Pol. considering the different altitudes, although RS presented a statistically significantly higher consume of these carbon sources, being the glycogen only used by these communities (Figure 1b). However, this was not the only substrate exclusively degraded by RS communities, consumption of $\beta$-methyl-D-glucoside and D-celobiose was also observed only in this soil type, suggesting a different metabolic behavior of microbial communities of BS and RS.

The CCA, based on metabolic data, showed anew a separation of the microbial communities according to the soil type (BS and RS) along the axis 1 (CCA 1; $70.0 \%$ ), being $\mathrm{MC}$ and $\mathrm{pH}$ the edaphic variables which significantly explained the sample ordination (Figure $2 b$, Table 2). Once again, soil samples from both altitudes were separated along axis 2 (CCA 2; 21.5\%), being the most influential factor OM (Figure 2b, Table 2). Also in this case, the canonical first axis and the sum of all the canonical axes exhibited statistical significance (Table 2). Strikingly, at metabolic level, RS samples were grouped together independently of the altitude, suggesting a plant filtering effect that exceeds the altitude effect observed in the case of BS samples.

\section{Discussion}

Several studies have shown that both, soil physicochemical characteristics and plant features affect the structure of microbial communities in the rhizosphere (e.g. Lorenzo et al., 2010; Min et al., 2013; Philippot et al., 2013), however few studies have been focused on the effect of environmental factors such as altitude on the genetic and metabolic diversity of microbial communities and how it could be modulated by the plant. In this study, the effect of altitude on microbial communities from two habitats, bulk and rhizosphere soils, were compared. Particularly, E. californica plants were chosen because of some reports in the literature suggesting that as invasive plants they strongly alter the chemical and physical properties of soils (Weidenhamer and Callaway, 2010); for example they roots produce isoquinoline alkaloids with antimicrobial activity (Fabre et al., 2000) which in turn may disturb the structure of soil microbial communities (e.g. Kuske et al., 2002; Batten et al., 2006; Lorenzo et al., 2010; Min et al., 2013). Interestingly, our results showed that archaeal and bacterial genetic diversities of rhizosphere soils (RS) were similar at both altitudes, but the fungal diversity increased at higher altitude. In contrast, bulk soils (BS) revealed no changes with altitude in the genetic diversity of any of the three microbial groups, which is in accordance with Shen et al. (2013) who did not find any elevational gradient 
tendency in soil bacterial diversity, being $\mathrm{pH}$ the main factor controlling bacterial diversity and community composition. In our study, $\mathrm{CCA}$ revealed that $\mathrm{pH}$ and moisture content were the most influential edaphic factors in soil samples ordination according to altitude, but a major separation of RS samples was observed suggesting that the rhizosphere effect could increase these differences probably due to physiological changes of the plant at higher altitude (2000 m.a.s.1.) rather than altitude per se.

Indeed, changes on diversity of soil microbial communities could be consequences of environmental limitations imposed by altitude on plants (Körner, 2007). Despite molecular mechanisms involved in the feedback loops between E. californica and soil microbial diversities remain unknown, it is important to note that $\mathrm{pH}$ has been reported as the best descriptor of soil microbial diversity and richness beyond other edaphic factors (Fierer and Jackson, 2006; Lauber et al., 2009).

Curiously, in the case of metabolic diversity, differences in the utilization of carbohydrates were observed in both soil types, RS samples from both altitudes were clustered together suggesting a plant filtering effect that reduces the differences observed between BS communities. Rhizosphere is a microenvironment strongly influenced by secondary metabolites such as alkaloids secreted by the plant root system, which have a significant influence on soil properties and microbial communities (Garbeva et al., 2008; Haichar et al., 2014; Bais et al., 2006) and whose biosynthesis can be triggered by biotic and abiotic elicitors (Badri and Vivanco 2009; Ribera and Zuñiga, 2012).

Although a high diversity of alkaloids for $E$. california has been described (Hagel and Facchini, 2013), altitude has not been reported as an elicitor in exudate production by this exotic species as in other plants whose exudate production was sensitive to factors related to the altitude, i.e. UV radiation (Rinnan et al., 2006), temperature (Kuzyakov et al., 2007), or soil moisture (Reid, 1974).

However, differences in some plant features, mainly floral and vegetative characters, have been observed among E. california populations located at different altitudes in the same sampling area of our study (Peña-Gómez and Bustamante, 2012). Some differences of these phenotypic traits related with a decrease in reproductive effort (biomass/flower size and flower number) would suggest that populations at higher altitude could have limitations in obtaining resources (Hiraga and Sakai, 2007) and this stress condition could indirectly affect rhizosphere microbial assemblages.

In general, our results suggest that metabolic diversity of the bulk soil communities is more sensitive to altitude than genetic diversity, but the plant is able to modulate this effect, probably as a consequence of altitude-related environmental factors that affect the physiology of the plant. In this sense, rhizosphere could be a relevant factor to moderate the indirect effect of altitude on soil microbial communities through edaphic factors such as soil moisture or $\mathrm{pH}$ which cannot be considered per se as altitudedependent environmental factors (Körner, 2007).

Considering that plant-soil microorganisms interaction plays a relevant role in colonization, adaptation and propagation of plant species and there is a growing interest in identifying the factors that determine the success of invasive plants; the impact of exotic plants on the structure of soil microbial communities is a topic of current interest. Nevertheless, specific effects produced by altitude on soil microorganisms through factors such as radiation or atmospheric pressure should be examined in further studies. 


\section{Conclusions}

Altitude modifies genetic and metabolic diversity patterns of soil microbial communities, although environmental factors such as $\mathrm{pH}$ and soil moisture, which appeared affecting microbial communities, would be mainly related with a rhizosphere effect. Therefore, E. californica would act as an ecological filter decreasing the altitude effect observed in the case of the bulk soil.

\section{Acknowledgments}

The authors acknowledge the assistance of M. Sc. Felipe Farías and Ms. Juana Leal for field and laboratory assistance, respectively. The research was funded by the postdoctoral project FONDECYT 3110140 . Ramiro Bustamante acknowledges the partial support of the Institute of Ecology and Biodiversity (PO5-002).

\section{References}

Alcantara, J., Bir, D.A., Franceschi, V.R., Facchini, P.J. 2005. Sanguinarine biosynthesis is associated with the endoplasmic reticulum in cultured opium poppy cells after elicitor treatment. Plant Physiol. $138,173-83$

Arroyo, M.T.K., Marticorena, C., Matthei, O., Cavieres, L. 2000. Plant invasions in Chile: present patterns and future predictions. In: Mooney H.A., R.J. Hobbs (eds). Invasive species in a changing world. Island Press, Covelo, California, USA, pp: 385-421.

Badri, D.V., Vivanco, J.M. 2009. Regulation and function of root exudates. Plant Cell Environ. 32, 666-681.

Bais, H., Weir, T.L., Perry, L.G., Gilroy, S., Vivanco, J.M. 2006. The role of root exudates in rhizosphere interactions with plants and other organisms. Annu. Rev. Plant Biol. 5, 233-266.
Baker, G.C., Smith, J.J., Cowan, D.A. 2003. Review and re-analysis of domain-specific $16 \mathrm{~S}$ primers. J. Microbiol. Methods. 55, 541-555.

Batten, K.M., Scow, K.M., Davies, K.F., Harrison, S.P. 2006. Two invasive plants alter soil microbial community composition in serpentine grasslands. Biol. Invasions. 8, 217-230.

Bintrim, S.B., Donohue, T.J., Handelsman, J., Roberts, G.P., Goodman, R.M. 1997. Molecular phylogeny of Archaea from soil. Proc. Natl. Acad. Sci. USA 94, 277-282.

Castillo, M.L.C., Peña-Gómez, F.T., Gutiérrez, V.L., Reyes, C.A., Arredondo-Núñez, A., Marey, M. 2013. Negative photoblastism in the invasive species Eschscholzia californica Cham. (Papaveraceae): Patterns of altitudinal variation in native and invasive range. Gayana Botanica. 70, 287-293.

Fabre, N., Claparols, C., Richelme, S., Angelin, M. L., Fouraste, I., Moulis, C. 2000. Direct characterization of isoquinoline alkaloids in a crude plant extract by ion-pair liquid chromatography-electrospray ionization tandem mass spectrometry: example of Eschscholzia californica. J. Chromatogr. A. 904, 35-46.

Fierer, N., Jackson, R. 2006. The diversity and biogeography of soil bacterial communities. Proc. Natl. Acad. Sci. USA 103, 626-63.

Fierer, N., McCain, C.M., Meir, P., Zimmermann, M., Rapp, J.M., Silman, M.R., Knight R. 2011. Microbial elevational diversity does not follow the biogeographical trends of plants and animals. Ecology. 92, 797-804.

Garbeva, P., van Elsas, J.D., van Veen, J.A. 2008. Rhizosphere microbial community and its response to plant species and soil history. Plant Soil. 302, 19-32.

Garland, J.L., Mills, A.L. 1991. Classification and characterization of heterotrophic microbial 
communities on the basis of patterns of community-level sole-carbon-source utilization. Appl. Environ. Microbiol. 57, 2351-2359.

Grytnes, J.A. 2003. Species-richness patterns of vascular plants along seven altitudinal transects in Norway. Ecography. 26, 291-300.

Hagel, J.M., Facchini, P.J. 2013. Benzylisoquinoline alkaloid metabolism: a century of discovery and a brave new world. Plant Cell Physiol. 54, 647-672.

Hagn, A., Pritsch, K., Ludwig, W., Schloter, M. 2003. Theoretical and practical approaches to evaluate suitable primer sets for the analysis of soil fungal communities. Acta Biotechnol. 23, 373-381.

Haichar, F. Z., Santaella, C., Heulin, T., Achouak, W. 2014. Root exudates mediated interactions belowground. Soil Biol. Biochem. 77, 69-80.

Hiraga, T., Sakai, S. 2007. The effects of inflorescence size and flower position on biomass and temporal sex allocation in Lobelia sessiliflora. Plant. Ecol. 188, 205-214.

Körner, C. 2007. The use of "altitude" in ecological research.Trends Ecol. Evol. 22, 569-574

Kuske, C.R., Ticknor, L.O., Miller, M.E., Dunbar, J.M., Davis, J.A., Barns, S.M., Belnap, J. 2002. Comparison of soil bacterial communities in rizhospheres of three plant species and the interspaces in an arid grassland. Appl. Environ Microbiol. 68, 1854-1863.

Kuzyakov, Y., Hill, P.W., Jones, D.L. 2007. Root exudate components change litter decomposition in a simulated rhizosphere depending on temperature. Plant Soil. 290, 293-305.

Lauber, C. L., Hamady, M., Knight, R., Fierer, N. 2009. Pyrosequencing-based assessment of soil $\mathrm{pH}$ as a predictor of soil bacterial community structure at the continental scale. Appl. Environ. Microbiol. 75, 5111-5120.
Leger, E. A., Rice, J. 2007. Assessing the speed and predictability of local adaptation in invasive California poppies (Eschscholzia californica). J. Evolution Biol. 20, 1090-1103.

Liu, W.T., Marsh, T.L., Cheng, H., Forney, L.J. 1997. Characterization of microbial diversity by determining terminal restriction fragment length polymorphisms of genes encoding 16S rRNA. Appl. Environ. Microbiol. 63, 4516-4522.

Lomolino, M. 2001. Elevation gradients of speciesdensity: historical and prospective views. Global Ecol. Biogeogr. 10, 3-13.

Lorenzo, P., Rodríguez-Echeverría, S., González L., Freitas, H. 2010. Effect of invasive Acacia dealbata Link on soil microorganisms as determined by PCR-DGGE. Appl. Soil Ecol. 44, 245-251.

Martínez-Viveros, O., Jorquera, M.A., Crowley, D.E., Gajardo, G., Mora, M.L. 2010. Mechanisms and practical considerations involved in plant growth promotion by rhizobacteria. J. Soil Sci. Plant Nutr. 10, 293-319.

McCain, C.M. 2005. Elevational gradients in diversity of small mammals. Ecology. 86, 366-372.

Min, L., Xiao-mei, X., Ying. P., Juan-juan, C., Na, C. 2013. Characteristics of soil microbial community functional and structure diversity with coverage of Solidago canadensis L. J. Cent.South Univ. T. 20, 749-756.

Orlando, J., Chávez, M., Bravo, L., Guevara, R., Carú, M. 2007. Effect of Colletia hystrix (Clos), a pioneer actinorhizal plant from the Chilean matorral, on the genetic and potential metabolic diversity of the soil bacterial community.Soil Biol. Biochem. 39, 2769-2776.

Peña-Gómez, F.T., Bustamante, R.O. 2012. Life history variation and demography of the invasive plant Eschscholzia californica Cham. (Papaveraceae), in two altitudinal extremes, Central Chile. Gayana Botanica. 69, 113-122. 
Philippot, L., Raaijmakers, J.M., Lemanceau, P., van der Putten, W.H. 2013. Going back to the roots: the microbial ecology of the rhizosphere. Nat. Rev. Microbiol. 11, 789-799.

Quiroz, C.L., Pauchard, A., Marticorena, A. Cavieres, L.A. 2009. Manual de plantas invasoras del centro-sur de Chile. Laboratorio de Invasiones Biológicas. Concepción, Chile. 45 pp.

Reid, C.P.P. 1974. Assimilation, distribution, and root exudation of ${ }^{14} \mathrm{C}$ by ponderosa pine seedlings under induced water stress. Plant Physiol. 54, 44-49.

Ribera, A. E., Zuñiga, G. 2012. Induced plant secondary metabolites for phytopatogenic fungi control: a review. J. Soil Sci. Plant Nutr. 12, 893911.

Rinnan, R., Gehrke, C., Michelsen, A. 2006.Two mire species respond differently to enhanced ultraviolet-B radiation: effects on biomass allocation and root exudation. New Phytol. 169, 809-818.

Shen, C., Xionga, J., Zhanga, H., Fenga, Y., Lina, X., Lib, X., Liangb, W., Chu, H. 2013. Soil pH drives the spatial distribution of bacterial communities along elevation on Changbai Mountain. Soil Biol. Biochem. 57, 204-211.

Shen, C., Ni, Y., Liang, W., Wang, J., Chu, H. 2015. Distinct soil bacterial communities along a smallscale elevational gradient in alpine tundra. Front. Microbiol. DOI: 10.3389/fmicb.2015.00582.

Singh, D., Lee-Cruz, L., Kim, W-S., Kerfahi, D., Chun, J-H., Adams, J.M. 2014. Strong elevational trends in soil bacterial community composition on Mt. Halla, South Korea. Soil Biol. Biochem. 68, 140-149.

Smit, E., Leeflang, P., Glandorf, B., VanElsas, J.D., Wernars, K. 1999. Analysis of fungal diversity in the wheat rhizosphere by sequencing of cloned PCR-amplified genes encoding 18S rRNA and temperature gradient gel electrophoresis. Appl. Eviron. Microbiol. 65, 2614-2621.

Vivanco, J.M., Bais, H.P., Stermitz, F.R., Thelen, G.C., Callaway, R.M. 2004. Biogeographical variation in community response to root allelochemistry: novel weapons and exotic invasion. Ecol. Lett. 7, 285-292.

Wang, J.T., Cao, P., Hu, H.W., Li, J., Han, L.L., Zhang, L.M., Zheng, Y.M., He, J.Z. 2015. Altitudinal distribution patterns of soil bacterial and archaeal communities along Mt. Shegyla on the Tibetan Plateau. Microb. Ecol. 69, 135-145.

Weidenhamer, J.D, Callaway, R.M., 2010. Direct and indirect effects of invasive plants on soil chemistry and ecosystem function. J. Chem. Ecol. 36, 59-69.

Weisburg, W.G, Barns, S.M., Pelletier, D.A., Lane, D.J. 1991. 16S ribosomal DNA amplification for phylogenetic study. J. Bacteriol. 173, 697-703.

Zhang, Y., Cong, J., Lu, H., Li, G., Qu, Y., Su, X., Zhou, J., Li, D. 2014. Community structure and elevational diversity patterns of soil Acidobacteria. J. Environ. Sci. 26, 1717-1724. 